\title{
Kinetic calculations for the thermal decomposition of calcium propionate under non-isothermal conditions
}

\author{
NIU ShengLi, HAN KuiHua \& LU ChunMei* \\ National Engineering Laboratory for Coal-Burning Pollutants Emission Reduction, Shandong University, Jinan 250061, China
}

Received February 3, 2010; accepted April 19, 2010

\begin{abstract}
Calcium propionate (CP) is shown to be useful for simultaneous $\mathrm{SO}_{2} / \mathrm{NO}$ reduction in coal-fired power plants and its thermal decomposition characteristics are measured by thermogravimetric analysis in a feasibility study into more complete reduction of these hazardous gases. Calcium carbonate (CC), which has been used primarily for in-furnace desulfuration, was used for comparison. The thermal decomposition of this organic calcium-based sorbent began at low temperature, i.e. the carboxylic radical was evaporated from $565 \mathrm{~K}$ to $759 \mathrm{~K}$ for $\mathrm{CP}$ and the corresponding mass loss percentage was $47.79 \%$. The residual was subsequently decomposed to release carbon dioxide between $843 \mathrm{~K}$ and $1012 \mathrm{~K}$. The latter phase of the process occurred more readily than with $\mathrm{CC}$ because of the loose structure of $\mathrm{CP}$ resulting from evaporation of the carboxylic radical in the low temperature zone, which could be seen directly by scanning electron microscope. The maximum mass loss rates of this phase occurred at temperatures of $972 \mathrm{~K}$ and $1012 \mathrm{~K}$ for CP and CC, respectively. The Ozawa-Flynn-Wall method was used to calculate the activation energy during the thermal decomposition process at heating rates of 5, 7.5, 10 and $15 \mathrm{~K} / \mathrm{min}$. The result further confirmed the multistage characteristic of $\mathrm{CP}$ thermal decomposition, which could be seen in differential thermogravimetry curves. The reaction orders of CP in the conversion range 20\%-80\%, calculated using the Avrami theory were from 0.061 to 0.608 , smaller than those of $\mathrm{CC}$, which were 1.647 to 2.084 .
\end{abstract}

thermogravimetric, thermal decomposition, calcium propionate, activation energy, reaction order

Citation: Niu S L, Han K H, Lu C M. Kinetic calculations for the thermal decomposition of calcium propionate under non-isothermal conditions. Chinese Sci Bull, 2011, 56: 1278-1284, doi: 10.1007/s11434-010-4065-8

Sulfur dioxide $\left(\mathrm{SO}_{2}\right)$ and nitric oxide $(\mathrm{NO})$ emitted from coal-fired power plants cause serious environmental problems and therefore many technologies for the reduction of these two hazardous gases have been explored [1,2]. Among these technologies, the wet-spray of organic calcium-based sorbents has the potential for simultaneous $\mathrm{SO}_{2}$ and $\mathrm{NO}$ abatement. Calcium-based sorbents [3,4], such as calcium magnesium acetate (CMA), calcium acetate (CA), calcium formate $(\mathrm{CF})$, calcium benzoate $(\mathrm{CB})$ and calcium propionate $(\mathrm{CP})$, can produce hydrocarbon fragments $\left(\mathrm{CH}_{i}\right)$ and Ca-based compounds during pyrolysis and so can combine the reburning process for $\mathrm{NO}$ reduction and impregnation of Ca-based compounds into the furnace for $\mathrm{SO}_{2}$ capture. Thus,

*Corresponding author (email: cml@sdu.edu.cn) investment and the running costs could be significantly reduced if this technology could be extended to coal fired power plants. Nimmo et al. [3-6] conducted laboratoryscale experiments with a down-fired pulverized coal combustor operated at $80 \mathrm{~kW}$ to investigate the performance of the above organic sorbents for control of air-pollutant gases under a number of conditions, obtaining satisfactory results. CMA and CP have been used as the deicing agent and food preservative, respectively, and the recent researches showed these compounds could reduce both $\mathrm{SO}_{2}$ and NO. Increasing interest is being shown in these environment-friendly calcium salts. They achieved $70 \%-80 \% \mathrm{NO}$ and $\mathrm{SO}_{2}$ reduction efficiencies using wet-spray injection at a calcium-to-sulfur molar ratio of about 2 and a reburning fuel fraction of about $12 \%-16 \%$. However, this efficiency is 
unable to meet the increasingly rigorous criteria implemented by environmental protection authorities. Therefore, parallel measures must be taken to reduce $\mathrm{SO}_{2}$ and $\mathrm{NO}$ more completely. A detailed understanding of the thermal decomposition characteristics of these organic calcium-based sorbents is important, because this information is fundamental to the estimation of their performance in reducing the air-pollutant gas emission.

Thermogravimetric (TG) analysis [7-9] has been widely used for the preliminary assessment of the combustion/pyrolysis behavior of fossil fuel, biomass fuel, sewage sludge and other organic/inorganic compounds. From TG-DTG (differential thermogravimetry) curves, the initial and final mass loss temperatures, the maximum mass loss rate and its corresponding temperature can be deduced. These pieces of information are important in the application of TG analysis to industry. Although the kinetics of the thermal decomposition process is also an important property of calcium based organic sorbents, it is not frequently studied [10]. Therefore, the kinetic parameters, like the reaction model, $f(\alpha)$, the pre-exponential factor, $A$, the activation energy, $E$, and the reaction order, $n$, should be calculated from the TG-DTG curves to understand the mechanism of the thermal decomposition process in detail $[11,12]$.

TG analysis may be conducted under isothermal [13] or non-isothermal conditions [14-16]. In early research, the isothermal condition was usually performed but it would be inappropriate to use this if a physicochemical process reached its maximum reaction rate at the beginning of the transformation. Thus, the more accurate non-isothermal condition, in which the object is heated at a constantly increasing temperature, has become the dominant one used to determine kinetic parameters. In other words, the mass loss percentage (TG signal) is recorded continuously as a function of time or temperature during a given temperature programming rate (TPR).

Two mathematical approaches are used to calculate the kinetic parameters from TPR data, the model-fitting [17] and model-free (isoconversional) approaches [18]. In the modelfitting approach, the reaction model $f(\alpha)$ is pre-assumed and $E, A$ and $f(\alpha)$ are calculated together but not independently. Consequently, the values of $E$ and $A$ depend significantly on the selection of $f(\alpha)$, and each pair of $E$ and $A$ could produce good linear regression for the corresponding $f(\alpha)$ under the "kinetic compensation effect". In other words, this method was unable to provide a unique reaction to describe the reaction mechanism. At the same time, the pre-assumption of the $f(\alpha)$ brings about a second problem, that the selection of reaction model constrains the solid-state reaction to one ideal form, whereas $f(\alpha)$ is actually made up of series of parallel and sequential reactions. In the model-free approach, the activation energy is calculated without assuming a reaction model but at least three different heating rates must be adopted in experiments. The activation energy is then calculated at different conversion values.
The objective of this study was to investigate the thermal decomposition process of the organic calcium-based sorbent CP. Inorganic calcium carbonate (CC) was chosen for comparison. Considering that the dynamic investigations of $\mathrm{CP}$ have rarely been reported in previous studies, the activation energy during thermal decomposition was calculated using the isoconversional method of Ozawa-Flynn-Wall [18-20] at four different heating rates: 5, 7.5, 10 and $15 \mathrm{~K} / \mathrm{min}$. The reaction order was then calculated through the Avrami theory $[13,21,22]$ at seven temperature points. The conclusions of this study are expected to make contributions to industrial applications of this organic compound for the control of air-pollutant gases.

\section{Experimental}

The CP, produced by Feng-Rui Biochemical Corporation in Jiangsu Province of China, used in this research was an analytically pure material with a crystal water molecule with the formula $\left(\mathrm{CH}_{3} \mathrm{CH}_{2} \mathrm{COO}\right)_{2} \mathrm{Ca} \cdot \mathrm{H}_{2} \mathrm{O}$. $\mathrm{CC}$, produced by Bai-Shi Chemical Corporation in Shandong Province of China, was also analytically pure but did not contain crystal water. Both $\mathrm{CP}$ and $\mathrm{CC}$ were sieved to 75-90 $\mu \mathrm{m}$ and then dried in an oven for $2 \mathrm{~h}$. After these pretreatments they were stored in a sealed container at room temperature prior to use.

The experiments were conducted on a TGA/SDTA851e thermogravimetric analyzer, produced by Mettler Toledo Corporation in Switzerland, connected to a water cooling system. The protective and reactive gas parts and the schematic for the experimental system are presented in Figure 1. During the experiments, the thermal decomposition of $\mathrm{CP}$ and $\mathrm{CC}$ was carried out in the furnace of the analyzer as the determined temperature programming rate (TPR). Linear temperature heating rates of 5, 7.5, 10 and $15 \mathrm{~K} / \mathrm{min}$ were chosen to investigate the decomposition characteristics between 298.15 and $1273.15 \mathrm{~K}$. The initial sample was weighed to $10 \pm 0.1 \mathrm{mg}$ in an aluminum oxide crucible with a

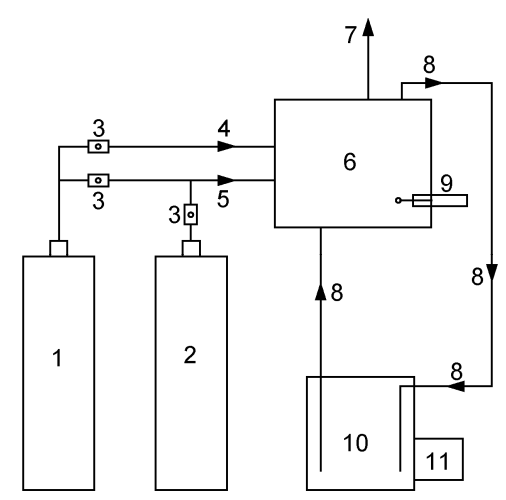

Figure 1 Schematic of the experimental thermogravimetric analysis system. $1, \mathrm{~N}_{2} ; 2, \mathrm{O}_{2} ; 3$, flowmeter; 4, reactive gas; 5, protective gas; 6 , TGA/SDTA851e; 7, flue gas; 8, circular cooling water; 9, sample feeder; 10 , water tank; 11, circularation pump. 
diameter of $5 \mathrm{~mm}$ and depth of $5 \mathrm{~mm}$ to avoid any furnace temperature variation generated by the sample itself. Furthermore, to eliminate the influence of the different sample weights on the result, the data deduced from the TG-DTG curves were normalized when dealing with values of mass loss and mass loss rate. The reaction atmosphere required in the chamber was met by mixing $\mathrm{O}_{2}\left(99.99 \%\right.$ purity) with $\mathrm{N}_{2}$ (99.99\% purity) at an $\mathrm{O}_{2}$ to $\mathrm{N}_{2}$ volume ratio of $1: 4$. The gas flux was kept constant at $120 \mathrm{~mL} / \mathrm{min}$ at atmospheric pressure to minimize mass-transfer effects. The chamber carrier gas, $\mathrm{N}_{2}(99.99 \%$ purity), was fixed at a flux of $30 \mathrm{~mL} / \mathrm{min}$.

The microstructural changes in $\mathrm{CP}$ before and after the evaporation of the carboxylic radical were analyzed with a scanning electron microscope (SEM) using a JSM-6610LV of JEOL.

\section{Results and discussion}

\subsection{CP and CC thermal decomposition characteristics}

It can be seen in Figure 2 that $\mathrm{CP}$ and $\mathrm{CC}$ presented different TG-DTG curves at a heating rate of $7.5 \mathrm{~K} / \mathrm{min}$ during the thermal decomposition process. The mass loss rate peak and the corresponding temperature of the three stages for $\mathrm{CP}$ and $\mathrm{CC}$ are summarized in Table 1.

Figure 2(a) shows the TG-DTG curves for the CP thermal decomposition process, which can be divided into three stages. Before the decomposition process, there was a net weight gain evident in the TG-DTG curves due to the physisorption and chemisorption of oxygen and water from the atmosphere on the surface of the solid material [23]. The first mass loss stage, due to evaporation of water of crystal-

Table 1 Mass loss rate peaks and corresponding temperatures of $\mathrm{CP}$ and $\mathrm{CC}$ during thermal decomposition ${ }^{\mathrm{a}}$

\begin{tabular}{ccccccc}
\hline Sample & Peak1 & Tem1 & Peak2 & Tem2 & Peak3 & Tem3 \\
\hline CP & $2.45 \times 10^{-4}$ & 377 & $7.35 \times 10^{-4}$ & 635 & $4.26 \times 10^{-4}$ & 972 \\
CC & - & - & - & - & $7.65 \times 10^{-4}$ & 1012 \\
\hline
\end{tabular}

a) Peak1: first mass loss rate peak, $\mathrm{s}^{-1}$; Tem1: temperature of first mass loss rate peak, K; Peak2: second mass loss rate peak, $\mathrm{s}^{-1}$; Tem2: temperature of second mass loss rate peak, K; Peak3: third mass loss rate peak, $\mathrm{s}^{-1}$; Tem3: temperature of third mass loss rate peak, $\mathrm{K}$. lization, occurred between 338 and $413 \mathrm{~K}$, causing a mass loss of $8.14 \%$. The mass loss rate peak in this stage was $2.45 \times 10^{-4} \mathrm{~s}^{-1}$ at $377 \mathrm{~K}$. As the temperature increased, the second mass loss stage occurred between 565 and $759 \mathrm{~K}$. During this phase, it is assumed that the organic component pentanone $\left(\mathrm{C}_{5} \mathrm{H}_{10} \mathrm{O}\right)$ was emitted from $\mathrm{CP}$, with stoichiometry $\left(\mathrm{CH}_{3} \mathrm{CH}_{2} \mathrm{COO}\right)_{2} \mathrm{Ca} \rightarrow \mathrm{CaCO}_{3}+\mathrm{C}_{5} \mathrm{H}_{10} \mathrm{O}$, because the $47.79 \%$ mass loss measured was very close to the ideal value of $46.24 \%$ for this thermal decomposition reaction $[6,11,24]$. It was also shown that the mass loss rate peak of $7.35 \times 10^{-4} \mathrm{~s}^{-1}$ at $635 \mathrm{~K}$ in this stage was the highest of the whole decomposition process. If temperature was increased furthermore, calcium carbonate would be decomposed into calcium oxide and carbon dioxide, $\mathrm{CaCO}_{3} \rightarrow \mathrm{CaO}+\mathrm{CO}_{2}$. This stage occurred mainly between $843 \mathrm{~K}$ and $1012 \mathrm{~K}$ and accounted for $23.76 \%$ of the mass loss, for which the ideal value is $23.65 \%$.

Figure 2(b) shows the TG-DTG curves for the CC thermal decomposition process. These clearly differ from the curves for $\mathrm{CP}$ because of the absence of carboxylic radicals, showing only one mass loss stage resulting from the decomposition of calcium carbonate into calcium oxide and carbon dioxide. This stage was similar to the third one in the $\mathrm{CP}$ thermal decomposition process, although thermal decomposition of $\mathrm{CP}$ occurred at a lower temperature zone than $\mathrm{CC}$, especially with respect to the rapid mass loss interval. The temperatures for maximum mass loss rate in the third stage were 972 and $1012 \mathrm{~K}$ for $\mathrm{CP}$ and $\mathrm{CC}$, respectively. This result may arise from the evaporation of the organic radicals from $\mathrm{CP}$ causing the initially compact structure to become loose enabling the release of carbon dioxide from the carbonate salts.

Based on the above description, it is concluded that the thermal decomposition of the organic calcium-based sorbent consisted essentially of two stages (disregarding the dehydration stage). The first stage involved the evaporation of a carboxylic radical, namely pentanone, in the lower temperature zone, yielding intermediate products $\mathrm{CH}_{i}$ and $\mathrm{CO}$ [6,24], which could transform $\mathrm{NO}$ into $\mathrm{N}_{2}$. As shown in Figure 3(b), CP was fractured and the residual sorbent became loose after the evaporation of the pentanone, which is
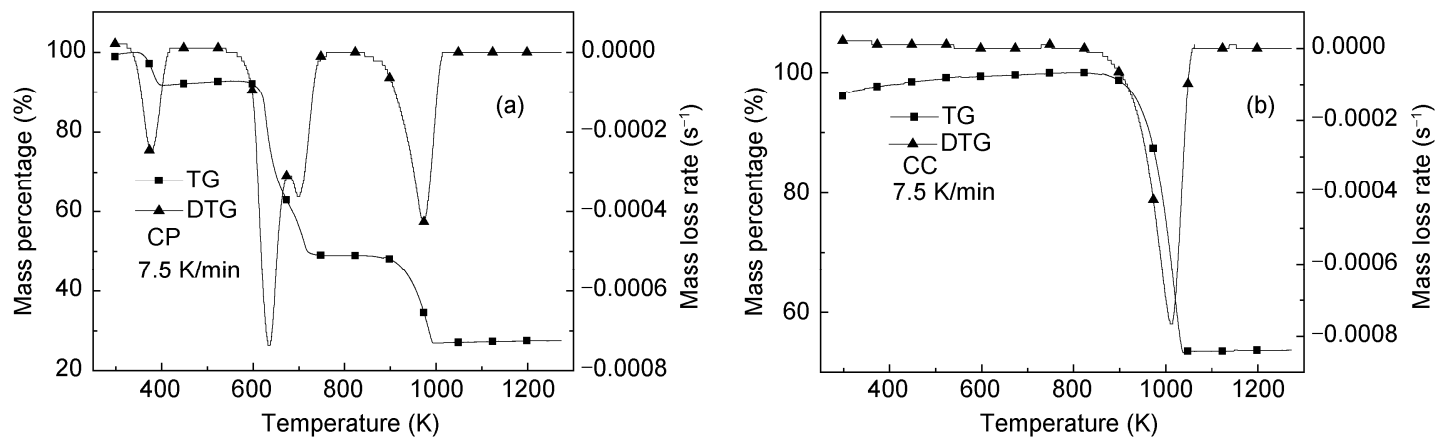

Figure 2 TG and DTG curves for the thermal decomposition of (a) CP and (b) CC. 

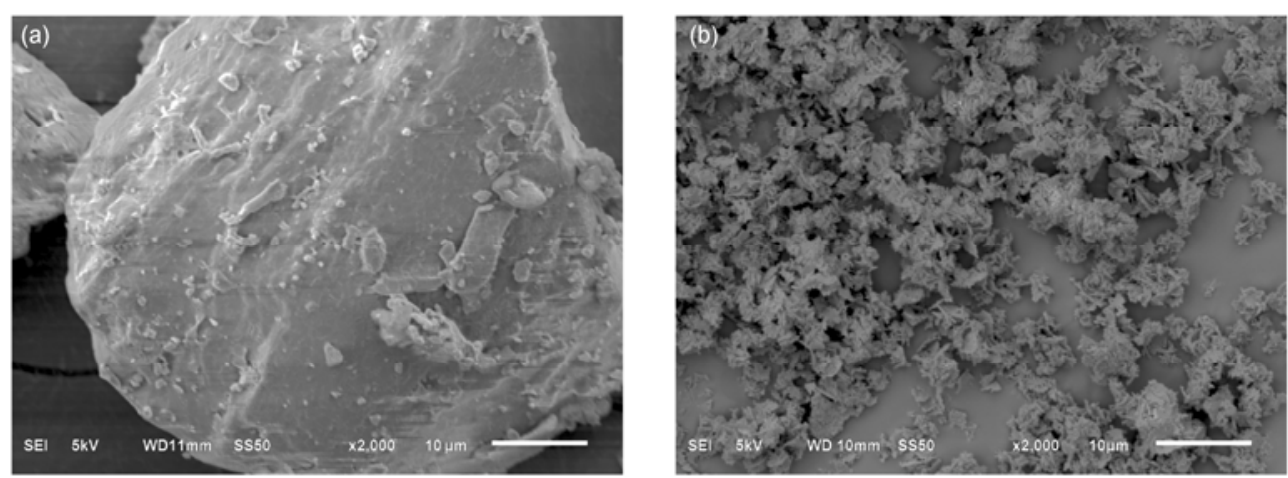

Figure 3 SEM images of CP (a) before and (b) after the evaporation of pentanone.

clearly shown by comparison with the sample before evaporation of pentanone (Figure 3(a)). Consequently, the decomposition of the carbonate salts occurred more easily in comparison with CC. Thus, the residual metal oxide gained a bigger core diameter and specific surface area, which could facilitate the desulfurization process [25]. This result is in agreement with the literature.

\subsection{Calculation of the activation energies for the thermal decomposition of $\mathrm{CP}$ and $\mathrm{CC}$}

The general kinetic equation for the heterogeneous solidstate thermal transformation in TPR can be described as [7,11-13,15,17-20,26,27]

$$
\frac{\mathrm{d} \alpha}{\mathrm{d} t}=k(T) \cdot f(\alpha) \rightarrow \beta \cdot \frac{\mathrm{d} \alpha}{\mathrm{d} T}=A \cdot \exp \left(-\frac{E}{R T}\right) \cdot f(\alpha),
$$

where $\alpha=\left(M_{0}-M_{\mathrm{t}}\right) /\left(M_{0}-M_{\mathrm{f}}\right)$ is the degree of reaction: $M_{\mathrm{t}}$ is the mass of the sample at time, $\mathrm{t}$, and temperature, $T ; M_{0}$ and $M_{\mathrm{f}}$ are the masses of the sample at the beginning and end of the mass loss reaction, respectively, the values of which can be obtained from the TG curves; $k(T)$ is the rate constant described by the Arrhenius equation, namely $k(T)=A \cdot \exp (-E / R T) ; A$ is the pre-exponential Arrhenius factor; $E$ is the activation energy; $R$ is the gas constant, $f(\alpha)$ is the reaction model; and $\beta$ is the temperature heating rate
( $\beta=\mathrm{d} T / \mathrm{d} t=$ constant $)$.

Eq. (1) can be transformed to

$$
\frac{\mathrm{d} \alpha}{f(\alpha)}=\frac{A}{\beta} \cdot \exp \left(-\frac{E}{R T}\right) \mathrm{d}(T)
$$

and then integrated to give conversion, as follows:

$$
\int_{0}^{\alpha} \frac{\mathrm{d} \alpha}{f(\alpha)}=g(\alpha)=\frac{A}{\beta} \cdot \int_{0}^{T} \exp \left(-\frac{E}{R T}\right) \mathrm{d} T .
$$

Several mathematical approaches could be used under non-isothermal experimental conditions to evaluate the kinetic parameters using the model-free method. The Ozawa-Flynn-Wall method [18-20], which used Dolye's approximation [28] for temperature integration, is the most commonly used. Eq. (3) can be transformed into

$$
g(\alpha)=\frac{A}{\beta} \cdot 0.00484 \exp \left(-1.052 \cdot \frac{E}{R T}\right) .
$$

Taking the logarithm and transposing, eq.(4) can then be rearranged to

$$
\ln (\beta)=\ln \left(\frac{A E}{R g(\alpha)}\right)-5.331-1.052 \cdot \frac{E}{R T} .
$$

To apply the method, four different temperature heating rates $(\beta)$, as described above, were chosen. For each value

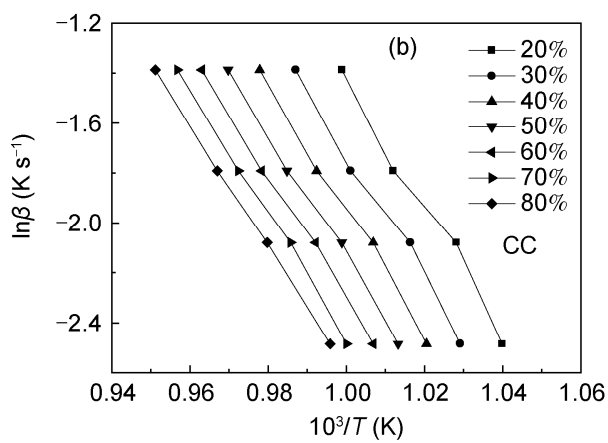

Figure 4 Curves fitted to the kinetic model proposed by the Ozawa-Flynn-Wall method for various conversion values corresponding to the thermal decomposition of (a) $\mathrm{CP}$ and (b) $\mathrm{CC}$ at temperature heating rates of 5, 7.5, 10 and $15 \mathrm{~K} / \mathrm{min}$. 
of $\alpha, \ln (\beta)$ plotted against $1 / T$ gave a straight line with a slope of $-1.052 E / R$ and the activation energy was thereby obtained as a function of conversion. Seven conversion values from $20 \%$ to $80 \%$ in increments of $10 \%$, were chosen for each sample at every heating rate to evaluate the activation energy. Plots of $\ln (\beta)$ versus $1 / T$ are shown in Figure 4 and the corresponding slopes for each conversion, obtained through linear regression, are presented in Table 2. The correlation coefficients $\left(R^{2}\right)$ and the deduced activation energy $(E)$ values are also presented in Table 2.

It is shown in Table 2 that the activation energy values for $\mathrm{CP}$ displayed larger variations than those for CC. This behavior indicates that the thermal decomposition process for $\mathrm{CP}$ was complex, consisting of several stages, each having different activation energies. However, the values for CC were essentially stable, which shows that the thermal decomposition process for $\mathrm{CC}$ was uniform over the investigated conversion range. The variations in activation energy values for $\mathrm{CP}$ and $\mathrm{CC}$ are consistent with the mechanisms for $\mathrm{CP}$ and $\mathrm{CC}$ thermal decomposition described above. Another feature of the results is that the correlation coefficient values for CC were higher than those for CP. This also confirms that the CC thermal decomposition was uniform but that $\mathrm{CP}$ decomposed in several distinct stages, with interaction between them.

\subsection{Calculation of the reaction orders for the thermal decomposition of $\mathrm{CP}$ and $\mathrm{CC}$}

As for the reaction order, the Avrami theory [13,21,22] was used in this study, as follows:

$$
\alpha=1-\exp \frac{-k(T)}{\beta^{n}},
$$

where $\alpha, k(T)$ and $\beta$ are as described in eq. (1) and the exponent, $n$, is the reaction order.

Taking the double logarithm and transposing, eq. (6) can be rearranged to yield

$$
\ln (-\ln (1-\alpha))=\ln A-\frac{E}{R T}-n \ln \beta .
$$

Plots of $\ln (-\ln (1-\alpha))$ versus $\ln \beta$ were established at the same temperature but at different heating rates and the slope value gave the reaction order. Seven temperature points were selected at each heating rate in the conversion range of $20 \%-80 \%$ for CP and CC, as shown in Figure 5 and the deduced values of $n$ are listed in Table 3 .

It can be seen from Table 3 that the reaction orders for $\mathrm{CP}$ were dependent on the extent of reaction, varying from 0.061 to 0.608 . These varying reaction order values indicate again that the thermal decomposition process for $\mathrm{CP}$ occurred in several stages. However, the values for CC varied within the narrower range 1.647-2.084, which indicates a more uniform process occurred during the thermal decomposition. The variable behavior of the reaction order is consistent with behavior observed with respect to the activation energy and the variations in reaction orders for $\mathrm{CP}$ were smaller than those for CC over the conversion range $20 \%$ to $80 \%$, overall. This may be because the thermal decomposition of $\mathrm{CP}$ began at a low temperature with the evaporation of the organic component, whereas the entire process oc-

\begin{tabular}{|c|c|c|c|c|c|c|c|c|c|}
\hline Sample & Conversion (\%) & Slope & $R^{2}$ & $E\left(\mathrm{~kg} \mathrm{~mol}^{-1}\right)$ & Sample & Conversion (\%) & Slope & $R^{2}$ & $E\left(\mathrm{~kg} \mathrm{~mol}^{-1}\right)$ \\
\hline \multirow{6}{*}{$\mathrm{CP}$} & 20 & -43.818 & 0.9840 & 346.30 & \multirow{6}{*}{$\mathrm{CC}$} & 20 & -25.569 & 0.9927 & 202.07 \\
\hline & 30 & -24.474 & 0.9806 & 193.42 & & 30 & -25.215 & 0.9956 & 199.28 \\
\hline & 40 & -11.169 & 0.9871 & 88.272 & & 40 & -25.138 & 0.9973 & 198.66 \\
\hline & 60 & -13.352 & 0.9643 & 105.53 & & 60 & -24.653 & 0.9987 & 194.84 \\
\hline & 70 & -13.949 & 0.9703 & 110.24 & & 70 & -25.017 & 0.9988 & 197.71 \\
\hline & 80 & -23.939 & 0.9998 & 189.19 & & 80 & -24.393 & 0.9997 & 192.78 \\
\hline
\end{tabular}

Table 2 Slopes and correlation coefficients $\left(R^{2}\right)$ and activation energy $(E)$ values corresponding to the linear regression of the curves in Figure 4
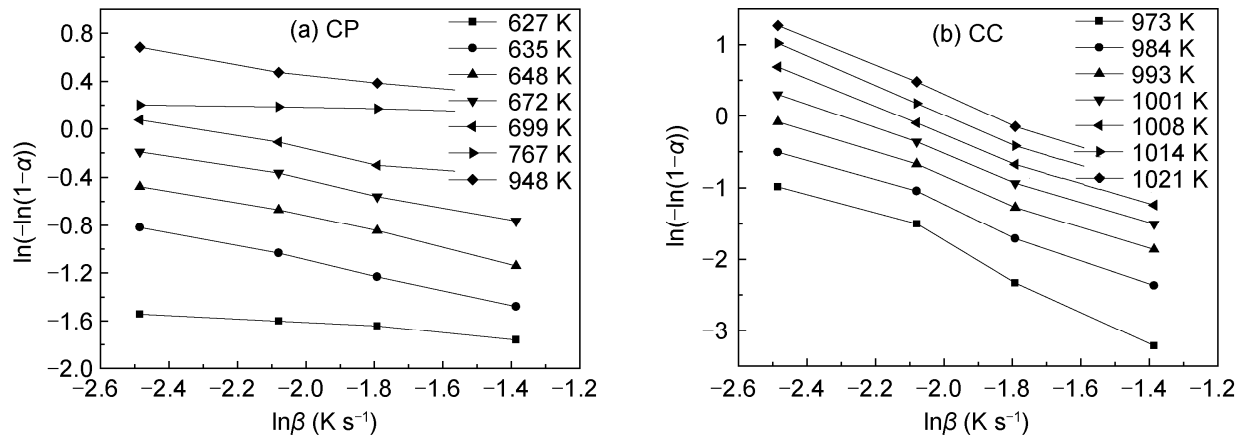

Figure 5 Fitted curves of the reaction order ( $n$ ) proposed by Avrami theory to seven temperature points corresponding to the thermal decomposition of (a) $\mathrm{CP}$ and (b) $\mathrm{CC}$ at temperature heating rates of $5,7.5,10$ and $15 \mathrm{~K} / \mathrm{min}$. 
Table 3 Reaction order $(n)$ for $\mathrm{CP}$ and $\mathrm{CC}$ at seven temperature points

\begin{tabular}{cccc}
\hline$T(\mathrm{~K})$ & $n(\mathrm{CP})$ & $T(\mathrm{~K})$ & $n(\mathrm{CC})$ \\
\hline 627 & 0.195 & 973 & 2.084 \\
635 & 0.608 & 984 & 1.736 \\
648 & 0.602 & 993 & 1.647 \\
672 & 0.532 & 1001 & 1.668 \\
699 & 0.436 & 1008 & 1.772 \\
767 & 0.061 & 1014 & 1.844 \\
948 & 0.362 & 1021 & 1.858 \\
\hline
\end{tabular}

curred over a broad temperature zone. On the other hand, the decomposition of $\mathrm{CC}$ occurred in a narrower, higher temperature zone. As a result, CC decomposed rapidly, whereas CP decomposed relatively slowly. However, it cannot be concluded that $\mathrm{CC}$ was less thermally stable because its decomposition temperature was much higher than that of $\mathrm{CP}$. Although the lower reaction order for CP made the decomposition process occur over a longer period, the multistage process enabled the dual $\mathrm{SO}_{2} / \mathrm{NO}$ abatement by $\mathrm{CP}$.

\section{Conclusions}

Thermal decomposition of calcium carbonate and the organic calcium-based sorbent of CP were studied through thermogravimetric analysis and the corresponding activation energies and reaction orders were also calculated. It was concluded that:

(1) The thermal decomposition of CP occurred in three stages. After dehydration, the second mass loss stage involved the evaporation of the carboxylic radical, where propionate was released between 565 and $759 \mathrm{~K}$. In the subsequent stage of CP decomposition, the release of carbon dioxide was facilitated by the looser structure of the organic material, compared with calcium carbonate, as evidenced by SEM images. This loose structure resulted from the evaporation of the carboxylic radical in the low temperature zone and the corresponding temperatures of the third mass loss rate peaks for $\mathrm{CP}$ and $\mathrm{CC}$ were $972 \mathrm{~K}$ and $1012 \mathrm{~K}$, respectively.

(2) Activation energies were calculated by the OzawaFlynn-Wall method, using isoconversional experiments conducted at four different heating rates 5, 7.5, 10 and 15 $\mathrm{K} / \mathrm{min}$. Seven activation energy values were evaluated for $\mathrm{CP}$ and $\mathrm{CC}$ from data measured at $10 \%$ increments between $20 \%$ and $80 \%$ conversion. The larger variation in the values obtained for $\mathrm{CP}$ indicate that a multistage of decomposition process occurred for the organic sorbents. At the same time, the reaction order was calculated using the Avrami theory and the corresponding values for $\mathrm{CP}$ and $\mathrm{CC}$ ranged from 0.061 to 0.608 and from 1.647 to 2.084 , respectively, over the conversion range $20 \%-80 \%$. In addition, the reaction orders calculated for $\mathrm{CP}$ were more variable than those for $\mathrm{CC}$ at the seven temperature points, consistent with the decomposition mechanisms deduced from the TG-DTG curves. Overall, the multistage CP thermal decomposition process enabled the simultaneous abatement of $\mathrm{SO}_{2}$ and $\mathrm{NO}_{x}$.

This work was supported by the Young Scholar Distinction for Ph.D Candidate of the Ministry of Education, the Shandong Province Natural Science Foundation (ZR2009FQ016, ZR2009FM001) and the Graduate Independent Innovation Foundation of Shandong University (GIIFSDU, yzc09067), China.

1 Han K H, Lu C M, Cheng S Q, et al. Effect of characteristics of calcium-based sorbents on the sulfuration kinetics. Fuel, 2005, 84: 1933-1939

2 Niu S L, Han K H, Lu C M. Experimental study on the effect of urea and additive injection for controlling nitrogen oxides emissions. Environ Eng Sci, 2010, 27: 47-53

3 Patsias A A, Nimmo W, Gibbs B M, et al. Calcium-based sorbents for simultaneous $\mathrm{NO}_{x} / \mathrm{SO}_{x}$ reduction in a down-fired furnace. Fuel, 2005, 84: 1864-1873

4 Li Y J, Zhao C S, Chen H C, et al. Modified CaO-based sorbent looping cycle for $\mathrm{CO}_{2}$ mitigation. Fuel, 2009, 88: 697-704

5 Nimmo W, Patsias A A, Hampartsoumian E, et al. Simultaneous reduction of $\mathrm{NO}_{x}$ and $\mathrm{SO}_{2}$ emissions from coal combustion by calcium magnesium acetate. Fuel, 2004, 83: 149-155

6 Nimmo W, Patsias A A, Hampartsoumian E, et al. Calcium magnesium acetate and urea advanced reburning for NO control with simultaneous $\mathrm{SO}_{2}$ reduction. Fuel, 2004, 83: 1143-1150

7 Otero M, Gomez X, Garcia A I, et al. Effects of sewage sludge blending on the coal combustion: A thermogravimetric assessment. Chemosphere, 2007, 69: 1740-1750

8 Chang Y, Bai Y P, Teng B, et al. A new drug carrier: Magnetite nanoparticles coated with amphiphilic block copolymer. Chinese Sci Bull, 2009, 54: 1190-1196

9 Fan C L, Li W, Li X, et al. Efficient photo-assisted Fenton oxidation treatment of multi-walled carbon nanotubes. Chinese Sci Bull, 2007, 52: 2054-2062

10 O'Connell C A, Dollimore D. A study of the decomposition of calcium propionate, using simultaneous TG-DTA. Thermochim Acta, 2000, 357: 79-87

11 Barkia H, Belkbir L, Jayaweera S A A. Non-isothermal kinetics of gasification by $\mathrm{CO}_{2}$ of residual carbon from timahdit and tarfay oil shale kerogens. J Therm Anal Calorim, 2004, 76: 623-632

12 Yagmur S, Durusoy T. Kinetics of the pyrolysis and combustion of Goynuk oil shale. J Therm Anal Calorim, 2006, 86: 479-482

13 Sheibani S, Ataie A, Heshmati-Manesh S. Kinetics analysis of mechano-chemically and thermally synthesized $\mathrm{Cu}$ by Johnson-MehlAvrami model. J Alloy Compd, 2008, 455: 447-453

14 Shen W, He H P, Zhu J X, et al. Preparation and characterization of 3-aminopropyltriethoxysilane grafted montmorillonite and acid-activated montmorillonite. Chinese Sci Bull, 2009, 54: 265-271

15 Niu S L, Lu C M, Han K H, et al. Thermogravimetric analysis of combustion characteristics and kinetic parameters of pulverized coals in oxy-fuel atmosphere. J Therm Anal Calorim, 2009, 98: 267-274

16 Tang P, Zhao Y C, Xia F Y. Thermal behaviors and heavy metal vaporization of phosphatized tannery sludge in incineration process. $\mathrm{J}$ Therm Anal Calorim, 2009, 20: 1146-1152.

17 Kok M V. Temperature-controlled combustion and kinetics of different rank coal samples. J Therm Anal Calorim, 2005, 79: 175-180

18 Otero M, Calvo L F, Gil M V, et al. Co-combustion of different sewage sludge and coal: A non-isothermal thermogravimetric kinetic analysis. Bioresource Technol, 2008, 99: 6311-6319

19 Simon P, Thomas P S, Okuliar J, et al. An incremental integral isoconversional method: Determination of activation parameters. $\mathrm{J}$ Therm Anal Calorim, 2003, 72: 867-874

20 Ramajo-Escalera B, Espina A, Garcia J R, et al. Model-free kinetics applied to sugarcane bagasse combustion. Thermochim Acta, 2006, 448: 111-116 
21 Ruitenberg G, Woldt E, Petfor-Long A K. Comparing the Johnson-Mehl-Avrami-Kolmogorov equations for iosthermal and linear heating conditions. Thermochim Acta, 2001, 378: 97-105

22 Lu M G, Shim M J, Kim S W. Curing behavior of an unsaturated polyester system analyzed by Avrami equation. Thermochim Acta, 1998, 323: 37-42

23 Jiang X M, Cui Z G, Han X X, et al. Thermogravimetric investigation on combustion characteristics of oil shale and high sulphur coal mixture. J Therm Anal Calorim, 2006, 85: 761-764

24 Nimmo W, Patsias A A, Hall W J, et al. Characterization of a process for the in-furnace reduction of $\mathrm{NO}_{x}, \mathrm{SO}_{2}$ and $\mathrm{HCl}$ by carboxylic salts of calcium. Ind Eng Chem Res, 2005, 44: 4484-4494

25 Han D H, Sohn H Y. Calcined calcium magnesium acetate as a superior $\mathrm{SO}_{2}$ sorbent: I. Thermal decomposition. AICHE J, 2002, 48: 2971-2977

26 Ozbas K E, Kok M V, Hicyilmaz C. Comparative kinetic analysis of raw and cleaned coals. J Therm Anal Calorim, 2002, 69: 541-549

27 Calvo L F, Otero M, Jenkins B M, et al. Heating process characteristics and kinetics of the rice straw in different atmospheres. Fuel Process Technol, 2004, 85: 279-291

28 Doyle C D. Kinetic analysis of thermogravimetric data. J Appl Polym Sci, 1961, 5: 285-292

Open Access This article is distributed under the terms of the Creative Commons Attribution License which permits any use, distribution, and reproduction in any medium, provided the original author(s) and source are credited. 